\title{
Type 2 (non-insulin-dependent) diabetes mellitus and coronary heart disease - chicken, egg or neither?
}

\author{
R. J. Jarrett \\ Department of Community Medicine, Guy's Hospital Medical School, London, UK
}

\begin{abstract}
Summary. Review of the literature yields much evidence against a correlation between duration of non-insulin-dependent diabetes mellitus (Type 2 diabetes) and the degree of coronary atherosclerosis or the risk of clinically evident coronary heart disease (CHD). Furthermore, an increased risk of CHD, similar to that in previously diagnosed diabetic subjects, has been demonstrated in persons with impaired glucose tolerance. These observations suggest that an increased risk of
\end{abstract}

CHD is not a consequence of the development of diabetes (i.e. persistent hyperglycaemia). It is more likely that diabetes develops in individuals who already possess characteristics which increase the risk of CHD in addition to the risk of developing diabetes.

Key words: Non-insulin dependent diabetes (Type 2 diabetes), coronary atherosclerosis, coronary heart disease, risk factors.
It is well known that diabetes is associated with an increased frequency of coronary heart disease (CHD) and a greater degree of coronary artery atherosclerosis and the subject has been recently reviewed $[1,2]$. The increased CHD risk associated with diabetes has been demonstrated in many countries, including Japan, where the general population risk is relatively low compared with Europe and North America. Migrant studies suggest that the low incidence in the Japanese - diabetic and non-diabetic - is due to environmental factors [3]. Studies in Britain $[4,5]$ and the USA $[6,7]$ indicate a relatively greater excess risk in diabetic women, but three European studies have noted similar excess risk in both sexes [8, 9, Reunanen - personal communication].

It is generally supposed that the extra risk in diabetes arises from a greater frequency and/or severity of 'risk factors' common to diabetic and non-diabetic subjects, such as hypertension, lipid abnormalities and haemostatic disorders. My proposition is that while the greater metabolic abnormalities in Type 1 (insulin-dependent) diabetes may be atherogenic, the relationship between CHD/atherosclerosis and Type 2 (non-insulindependent) diabetes is more complicated, and that Type 2 diabetes is associated with but not a cause of CHD.

\section{Duration of diabetes/hyperglycaemia}

If diabetes were causally related to atherosclerosis/ $\mathrm{CHD}$, it would be reasonable to assume that increasing duration of diabetes would increase the amount of atherosclerosis or the frequency of CHD, just as duration is related to the degree and frequency of microangiopathy in both major varieties of diabetes. The older literature concerning the relationship with duration is contradictory, no doubt in part because of failure to differentiate between diabetes types, compounded by the problem of accurately ascertaining duration in Type 2 diabetes. Furthermore, assessments of the effect of duration fail to take into account other possible confounding factors, such as age of onset of diabetes and age at manifestation of CHD. However, there are two studies which have compared diabetic patients diagnosed via a screening programme with those diagnosed by conventional means. It may be reasonably assumed that the former group is earlier in the course of diabetes than the latter. In Erfurt (GDR), 250 diabetic subjects diagnosed by a glycosuria screening programme were compared over 10 years of follow-up with matched control subjects diagnosed by ordinary clinical procedures [10]. Ten year mortality rates from all causes and from vascular disease were similar in both groups. In the Israeli Ischaemic Heart Disease Survey, 209 men, newly diagnosed by glucose tolerance test screening, were compared with 270 previously diagnosed patients from the same population [11]. During 5 years follow-up, the incidence of non-fatal myocardial infarction and infarction followed by death was similarly increased over matched non-diabetic subjects in both groups. The incidence of sudden death was higher in the previously 
diagnosed diabetic subjects, but the difference was not statistically significant.

In two other population studies, it was possible to compare CHD mortality rates in previously diagnosed male diabetic patients with those of men in the upper range of levels of glycaemia measured after an oral glucose load. Most of the people in this range would not be considered diabetic by current criteria, though they are at increased risk of subsequent development of diabetes. In the Whitehall Study (London, UK), 7.5 year age adjusted CHD mortality rates in known male diabetic subjects with an average duration of nearly 10 years were not significantly different from those in men in the upper five centiles of the blood glucose distribution [12]. Both groups had rates approximately twice those of men below the ninety-fifth centile. In the Honolulu Heart Program (Hawaii, USA) [13], a prospective study of Japanese men born in the years 1900-1919 and examined in 1965-1968, age-adjusted CHD mortality rates over 9 years of follow-up were not significantly different between men with previously diagnosed diabetes (mostly Type 2 ) and men with post-load hyperglycaemia (above the ninetieth centile) at examination. Both groups had mortality rates from CHD substantially and significantly greater than men with blood glucose values below the ninetieth centile.

In the Whitehall survey, a number of subjects with previously known diabetes participated (mostly Type 2). The age-adjusted 10-year mortality rates in these men, both from all causes and CHD, were approximately double those of the non-diabetic men. In the Type 2 diabetic subjects, there was no significant relationship between duration and mortality, whether from CHD or from any cause (Jarrett RJ, Shipley M: unpublished observations).

These studies thus provide no evidence for, but rather argue against, any effect of diabetes duration upon CHD incidence. With regard to the degree of atherosclerosis, most older studies are uninterpretable. Of the modern investigations which have addressed the question, the Five Towns Study (Prague, Czechoslovakia; Malmo, Sweden; Tallin, Yalta and Ryazan, USSR) [14] compared aortic and coronary atherosclerosis in diabetic patients with duration above and below 10 years. The authors observed no difference in aortic atherosclerosis, but coronary atherosclerosis was more extensive in the long duration group. Unfortunately, the potentially confounding effects of age, sex, treatment category and levels of blood pressure were not considered. The latter may well have been relevant, for in the study, coronary atherosclerosis was strongly related to 'hypertension', in both those with and without diabetes. Waller et al. [15] measured the degree of cross-sectional narrowing in the main coronary arteries due to atherosclerotic plaques of diabetic patients diagnosed above age 30 years and having had an autopsy at the Mayo Clinic (USA) during the period 1945-1975. In this study, the prevalence of severe stenosis $(>75 \%)$ of the left main coronary artery did not vary with the duration of diabetes (categories $1-5,6-10,11-25$ and $26-40$ years). This was also the case with the average frequency of severe stenosis affecting the three main coronary arteries. Age and treatment were not, apparently, confounding variables in this study, but blood pressure levels were not considered.

Vigorita et al. [16] performed a similar study but used the technique of post-mortem coronary angiography. Both the diabetic and age and sex-matched control subjects had undergone autopsy at the Johns Hopkins Hospital, Baltimore, USA, between 1968 and 1978. Twenty-two percent of all patients autopsied were studied, selection being predominantly 'the expectation of cardiac disease' and it can only be assumed that selective factors were identical for those with and without diabetes. All abnormalities were graded in relation to severity. Compared with the control subjects, the diabetic subjects had significantly more coronary atherosclerosis and more infarcts. Within the diabetic group, there were no significant differences according to treatment (nil, diet, oral agents, insulin) nor was there a significant association with the duration of diabetes, even by univariate analysis.

\section{Effect of risk factors in diabetic subjects}

There is some debate over the question whether subjects with Type 2 diabetes have more frequent or more severe risk factors for CHD [1]. Only three studies have reported the predictive effect of putative risk factors in diabetic subjects with specific reference to CHD. None separated the insulin-treated from the rest, but in each population, most subjects were not receiving insulin. In the Evans County study (USA) [17], 4.5-year CHD mortality rates when standardised for age, systolic blood pressure, serum cholesterol and triglyceride levels, body mass and smoking habit were not increased in diabetic men but were increased in diabetic women. This suggests a specific effect of diabetes only in females, but as there were only seven CHD deaths (four men, three women) any conclusion must be tentative.

In the Whitehall study, age adjusted 10-year incidence rates of fatal CHD were approximately doubled in known diabetic subjects. In this male working population, mean levels of blood pressure and plasma cholesterol and frequency of cigarette smoking were very similar to those in age-matched control subjects and the relationships of these risk factors to CHD mortality did not differ significantly between them (Jarrett RJ, Shipley $\mathrm{M}$ : unpublished observations). In the Honolulu study [13] when all subjects were included in multiple logistic analyses, both serum glucose level and "medication for diabetes' (insulin or oral hypoglycaemic therapy) remained significantly predictive of CHD mortality, despite the inclusion of many other predictive variables, including cholesterol level and electrocardiographic abnormalities. 
The Framingham, USA investigators examined the influence of several risk factors upon cardiovascular (not CHD specifically) morbidity and mortality and concluded that associated risk factors could not explain the higher incidence of disease in those known to have diabetes $[6,18]$.

It remains possible that some other measure, e.g. abnormal haemostasis [19] may explain the excess risk of CHD, but again it would be reasonable to suppose that increased exposure to this supposed risk factor (i.e. increasing duration of diabetes) would increase the observed risk. As discussed earlier, this does not seem to be the case.

\section{Pre-diagnosis}

It might be more profitable to consider the period before the diagnosis of diabetes. Among the few studies of non-diabetic populations subsequently followed up to the diagnosis of diabetes, the Israeli Ischaemic Heart Disease study [20] demonstrated that peripheral vascular disease and hypertension were more frequent in men who had glucose tolerance within the normal range at the time of study, but who subsequently became diabetic. In the Dupont Company study (USA) [21], retrospective analysis of medical records also showed hypertension to be more frequent in people subsequently diagnosed as diabetic. In the Framingham study [18] subjects with diabetes had higher lipid values and a higher frequency of hypertension before diagnosis.

Many people pass through a phase of impaired glucose tolerance before becoming overtly diabetic, though by no means all such subjects are pre-diabetic $[22,23]$. Comparisons of people with impaired glucose tolerance and age-matched control subjects have shown higher average blood pressures in the former [24] and in some studies higher average cholesterol levels as well [13,25]. A higher frequency of electrocardiographic abnormalities has also been observed in persons with impaired glucose tolerance $[12,13,26,27]$. As mentioned above, some prospective studies have found impaired glucose tolerance to be associated with increased morbidity and/or mortality rates. Although this has not been a universal finding [27], at least some of the discrepancies may be due to inadequate sample size in some studies. In contrast, impaired glucose tolerance is not a risk factor for diabetic microangiopathy over the time span in which the CHD risk is evident [28]. In addition, there are inter-correlations between blood glucose, blood pressure and plasma insulin levels and the latter have been shown to possess statistically, if not biologically, independent prediction for $\operatorname{CHD}[29,30]$.

Thus, Type 2 diabetes and impaired glucose tolerance appear to share a similar risk of CHD but a totally dissimilar risk of microangiopathy. Furthermore, Type 2 diabetic subjects emerge from groups in the population with higher than average frequencies of several risk fac- tors for CHD and with increased frequencies of existing CHD according to electrocardiographic evidence.

\section{Conclusions}

Much effort has been expended in comparing diabetic with non-diabetic subjects to see if factors are present in excess or deficiency in those with diabetes which might explain the greater risk of vascular disease, in particular CHD. While relevant differences have been observed, they are not consistent between studies. Furthermore, the prospective studies which have examined the predictive effect of the major known risk factors have failed to establish them as the explanation for the extra risk in diabetes.

The thesis that diabetes itself in some way confers the extra risk is further weakened by the equally increased risk demonstrated in groups of people with impaired glucose tolerance, amongst whom there is a higher frequency of existing CHD, higher than average blood pressure levels, possibly also of cholesterol levels, and an increased risk of episodes of CHD, of developing diabetes, or both. Thus, certain metabolic milieux predispose to the development of CHD and/or diabetes. As the degree of atherosclerosis appears to be greater in diabetic patients, even shortly after diagnosis, it is conceivable that atherosclerosis itself may predispose to the development of diabetes [14], though there is no direct evidence to support this hypothesis. It is more likely that atherosclerosis and diabetes share a number of antecedents, the balance between them determining the clinical outcome. One pre-existing factor which may sway the balance in the direction of diabetes is obesity, which has a much stronger relationship in prospective studies to the incidence of diabetes than to that of CHD [31]. The common antecedents date back to adolescence or before, for association between levels of blood pressure, blood glucose and plasma lipids have been demonstrated in the young as well as in adults [32-34]. For both serum cholesterol and blood pressure, there is evidence of tracking of level with increasing age [35, 36]. Thus, an adolescent with a 'normal' blood pressure level, but towards the upper end of the distribution, is likely to remain there and by middle-age to have entered the hypertensive 'at risk' range. If the analogy is correct, the newly-diagnosed diabetic patient of age 45 years may have 30 or more years of exposure to factors which promote atherogenesis. The final decompensation of blood glucose control which we recognise as diabetes, though generating the risk of microvascular disease, does not add to the risk of CHD.

In the context of this discussion, the recent observations of Owerbach et al. [37] may be relevant. These authors studied Type 2 diabetic patients and non-diabetic control subjects and found that the former had a higher frequency of $U$ alleles in the polymorphic region of chromosome 11. Furthermore, in both diabetic and con- 
trol subjects, the frequency of $U$ alleles was higher in those with 'macroangiopathy' (one or more of angina pectoris, myocardial infarction, intermittent claudication, cerebrovascular incident). If confirmed, this would add a genetic component to the concept of common antecedents for both Type 2 diabetes and atherosclerosis.

\section{References}

1. Jarrett RJ, Keen H, Chakrabarti R (1982) Diabetes, hyperglycaemia and arterial disease. In: Keen $H$, Jarrett $J$ (eds) Complications of diabetes, 2nd edn. Edward Arnold, London, pp 179-204

2. Ganda OmP (1980) Pathogenesis of macrovascular disease in the human diabetic. Diabetes 29:931-942

3. Kawate R, Yamakido M, Nishimoto $Y$, Bennett PH, Hamman RF, Knowler WC (1979) Diabetes mellitus and its vascular complications in Japanese migrants on the island of Hawaii. Diabetes Care 2: $161-170$

4. Jarrett RJ, McCartney P, Keen H (1982) The Bedford Survey: ten year mortality rates in newly diagnosed diabetics, borderline diabetics and normoglycaemic controls and risk indices for coronary heart disease in borderline diabetics. Diabetologia 22: 79-84

5. Shenfield GM, Elton RA, Bhalla IP, Duncan LJP (1979) Diabetic mortality in Edinburgh. Diab Metab 5: 149-158

6. Kannel WB, McGee DL (1979) Diabetes and cardiovascular risk factors: the Framingham Study. Circulation 59: 8-13

7. Barrett-Connor E, Wingard D (1982) Sex differential in ischemic heart disease death in diabetics: a prospective population-based study. In: Alberti KGMM, Ogada T, Aluoch JA, Mngola EN (eds) Abstracts 11th Congress of the International Diabetes Federation (1981) Excerpta Med Int Congr Ser 577, Excerpta Medica, Amsterdam, $\mathrm{p} 65$

8. Panzram G, Zabel-Langhennig R (1981) Prognosis of diabetes mellitus in a geographically defined population. Diabetologia 20: 587-591

9. Królewski AS, Czyzyk A, Janeczko D, Kopczyński J (1977) Mortality from cardiovascular diseases among diabetics. Diabetologia 13: $345-350$

10. Panzram G, Ruttmann B (1978) Prognose des Diabetes mellitus nach Frühdiagnose durch Glucosurie-Screening. Schweiz Med Wschr 108: 221-225

11. Herman JB, Medalie JH, Goldbourt U (1977) Differences in cardiovascular morbidity and mortality between previously known and newly diagnosed adult diabetics. Diabetologia 13: 229-234

12. Fuller JH, Shipley MJ, Rose G, Jarrett RJ, Keen H (1980) Coronary heart disease risk and impaired glucose tolerance. Lancet 1: 1373-1376

13. Yano K, Kagan A, McGee D, Rhoads GG (1982) Glucose intolerance and nine-year mortality in Japanese men in Hawaii. Am J Med 72: 71-80

14. Zdanov VS, Vihert AM (1976) Atherosclerosis and diabetes mellitus. Bull WHO 53: 547-553

15. Waller BF, Palumbo PJ, Lie JT, Roberts WC (1980) Status of the coronary arteries at necropsy in diabetes mellitus with onset after age 30 years: analysis of 229 diabetic patients with and without clinical evidence of coronary heart disease and comparison to 183 control subjects. Am J Med 69: 498-506

16. Vigorita VJ, Moore GW, Hutchins GM (1980) Absence of correlation between coronary arterial atherosclerosis and severity or duration of diabetes mellitus of adult onset. Am J Cardiol 46: $535-542$

17. Heyden S, Heiss G, Bartel AG, Hames CG (1980) Sex differences in coronary mortality among diabetics in Evans County, Georgia. J Chron Dis 33: 265-273

18. Garcia MJ, McNamara PM, Gordon T, Kannel WB (1974) Mor- bidity and mortality in diabetics in the Framingham population. Sixteen year follow-up study. Diabetes 23: 105-111

19. Fuller JH, Keen H, Jarrett RJ, Omer T, Meade TW, Chakrabarti R, North WRS, Stirling Y (1979) Haemostatic variables associated with diabetes and its complications. Br Med J 2: 964-966

20. Medalie JH, Papier CM, Goldbourt U, Herman JB (1975) Major factors in the development of diabetes mellitus in 10000 men. Arch Int Med 135: 811-817

21. Pell S, d'Alonzo CA (1967) Some aspects of hypertension in diabetes mellitus. J Am Med Assoc 202: 104-110

22. Jarrett RJ, Keen H, Fuller JH, McCartney M (1979) Worsening to diabetes in men with impaired glucose tolerance (borderline diabetes). Diabetologia 16:25-30

23. Keen H, Jarrett RJ, McCartney P (1982) The ten-year follow-up of the Bedford Survey (1962-1972): Glucose tolerance and diabetes. Diabetologia 22: 73-78

24. Jarrett RJ, Keen H, McCartney M, Fuller JH, Hamilton PJS, Reid DD, Rose G (1978) Glucose tolerance and blood pressure in two population samples: their relation to diabetes mellitus and hypertension. Int J Epidemiol 7: 15-24

25. Ostrander LD, Lamphiear DE, Block WD, Williams GW, Carman WJ (1980) Physiological variables and diabetic status: findings in Tecumseh, Mich. Arch Intern Med 140: 1215-1219

26. Keen H, Rose GA, Pyke DA, Boyns, DR, Chlouverakis C, Mistry S (1965) Blood sugar and arterial disease. Lancet 2: 505-508

27. Stamler R, Stamler J (eds) (1970) Asymptomatic hyperglycemia and coronary heart disease. J Chron Dis 32: 683-837

28. Al Sayegh H, Jarrett RJ (1979) Oral glucose-tolerance tests and the diagnosis of diabetes: results of a prospective study based on the Whitehall Survey. Lancet 2: 431-433

29. Pyöräla K, Savolainen E, Kaukola S, Haapakoski J (1982) High plasma insulin as coronary heart disease risk factor. In: Eschwege E (ed) Advances in diabetes epidemiology. Elsevier Biomedical Press, Amsterdam New York Oxford, pp 143-148

30. Ducimetiere P, Eschwege E, Richard J, Rosselin G, Claude JR (1982) Clinical complications of coronary heart disease according to plasma insulin and glucose levels. A further analysis of the $\mathrm{Pa}$ ris Prospective Study. In: Eschwege E (ed) Advances in diabetes epidemiology. Elsevier Biomedical Press, Amsterdam New York Oxford, pp 149-155

31. Larson B, Björntorp P, Tibblin G (1981) The health consequences of obesity. Int J Obesity 5: 97-116

32. Florey C du V, Uppal S, Lowy C (1976) Relation between blood pressure, weight, and plasma sugar and serum insulin levels in school children aged 9-12 years in Westland, Holland. Br Med J 1: $1368-1371$

33. Voors AW, Radhakrishnamurthy B, Srinavasan SE, Webber LS, Berenson GS (1981) Plasma glucose level related to blood pressure in 272 children, ages $7-15$ years, sampled from a total biracial population. Am J Epidemiol 113: 347-356

34. Tzagournis M, Chiles R, Ryan JM, Skillman TG (1968) Interrelationships of hyperinsulinism and hypertriglyceridemia in young patients with coronary heart disease. Circulation 38:1156-1163

35. Gillum RF, Taylor HL, Brozek J, Anderson J, Blackburn H (1982) Blood lipids in young men followed 32 years. J Chron Dis 35 635-641

36. Gillum RF, Taylor HL, Brozek J, Polansky P, Blackburn H (1982) Indices of obesity and blood pressure in young men followed 32 years. J Chron Dis 35: 211-219

37. Owerbach D, Johansen K, Billesbølle P, Poulsen S, Schroll M, Nerup J (1982) Possible association between DNA sequences flanking the insulin gene and atherosclerosis. Lancet 2: 1291-1293

Dr. R. J. Jarrett

Department of Community Medicine

Guy's Hospital Medical School

London SE1 9RT

UK 